\begin{tabular}{|c|c|c|}
\hline$A$ & $\begin{array}{c}\text { International Journal of Current Research } \\
\text { and Academic Review }\end{array}$ & sister \\
\hline $\begin{array}{l}\text { EXCELLENT } \\
\text { PUBLISHERS } \\
\end{array}$ & $\begin{array}{c}\text { ISSN: 2347-3215 (Online):, Volume } 5:, ; \text { Number } 8 \text { (August-2017) } \\
\text { Journal homepage: http://www.ijcrar.com }\end{array}$ & \\
\hline
\end{tabular}

doi: https://doi.org/10.20546/ijcrar.2017.508.009

\title{
Esophageal Atresia and Tracheoesophageal fistula: Gap Length and Clinical Outcome (A Prospective Study among Group of Iraqi Neonates)
}

\author{
Hayder Neamah Hassan Al-Khayyat*
}

FIBMS, College of Medicine - University of Kufa, Specialist Pediatric Surgeon Al-Zahra'a Teaching Hospital, Iraq

*Corresponding author

\begin{abstract}
In surgical practices in management of esophageal atresia with or without tracheoesophageal fistula, the gap length between the two ends play an important role in the management modality and also affect the outcome of surgery. We aimed to assess the critical gap length for the safe esophageal anastomosis and assess the outcome of the patients after intervention. This was a prospective study continued from February, 2011 to September, 2013 and included 25 neonates ( 7 males and 18 females) who had Esophageal atresia with distal tracheaoesophageal fistula who were admitted in Al Zahra a teaching hospital, in Al -Najaf province, middle of Iraq. The gap length was measured without mobilization of oesophagus, and patients were categorized into three groups according to the gap length, group I (gap length $<2 \mathrm{~cm})$, group II $(2-3 \mathrm{~cm})$ and group III $(>3 \mathrm{~cm})$. Tracheoesophageal fistula was identified and closed. These complications were mainly found in patients of Groups II and III.
\end{abstract}

\section{Article Info}

Accepted: 30 July 2017

Available Online: 20 August 2017

\section{Keywords}

Esophageal atresia,

Tracheoesophageal fistula, Management,

Gap length

\section{Introduction}

Esophageal atresia (EA) is significant severe developmental defect affected almost one in 4000 newborns, wheather or not abnormally connected to the trachea, Tracheo-esophageal fistula (TEF) The prevalence of varies across different countries and even in the same geographical area, for instance in Britain the estimates of five regions ranged 0.7 to 3.2 per 10000 live births (Nassar et al., 2012; Rankin et al., 2005). The EA characterized by the loss of continuity of upper gastrointestinal tract which is often associated with persistent connection, or fistula between trachea and esophagus. Newborn with congenital EA/ TEF usually presented with shortly after birth with abundant secretions in the mouth, coughing, cyanosis, vomiting and or respiratory distress, (Kim et al., 2017) The diagnosis could be established prenatally when a proper ultrasonography examination was made, the diagnosis of EA/TEF may be suspected when the ultrasound examination reveals polyhydramnios, absence of a fluid filled stomach, esophageal pouch distention, low fetal weight than that normally expected and a small abdomen (Pinheiro et al., 2012; Scott 2014; Spitz 2007) There are two classifications used, the primary types of congenital EA are : EA with distal TEF (85\%, Vogt IIIb, Gross C), isolated EA without TEF (8\%, Vogt II, Gross A), TEF without atresia or H-type TEF (4\%, Gross E), EA with proximal TEF (3\%, Vogt III, Gross B) and and EA with proximal and distal TEF ( $<1 \%$, Vogt IIIa, Gross) (Pinheiro et al., 2012). Management of EA/TEF is surgical, however, the surgical intervention considered urgent but not emergency (Pinheiro et al., 2012). The primary correction of EA and TEF is the best treatment 
option in the absence of severe malformations (Seitz et al., 2006). Most infants with EA/TEF undergo repair in early infancy, with division of the TEF and primary esophageal anastomosis. Patients with EA and wide separation of the esophageal ends continue to represent a major surgical challenge. Lengthening procedures, with or without esophagomyotomy, may be used to allow esophageal anastomosis. Neonatal esophageal stretching has been reported to allow primary anastomosis of the esophagus even in infants with long-gap EA/TEF (Foker et al., 1997). The gap length between the two ends of esophagus play an important role in the management modality and also affect the outcome of surgery (Mansur et al., 2005). However, it is not usually possible to apply a successful anastomosis between the two ends without elongating the esophagus in cases with long gap EA. On the other hand, gap length plays a major role in determining the outcome of the treatment, hence the current study tried to assess the critical gap length for the safe esophageal anastomosis.

\section{Patients and Methods}

A prospective study included twenty five neonates with Esophageal atresia distal tracheaoesophageal fistula were admitted to the department of Pediatric Surgery, Al Zahra`a teaching hospital, in najaf over the period February, 2011 to September, 2013. Two cases of isolated esophageal atresia admitted during the period were not included in the study. All the neonates were thoroughly examined at the time of admission and their physical findings were noted. Special emphasis was laid on the body weight, respiratory status and associated congenital anomalies, especially cardiac, renal and gastrointestinal malformations. They were resuscitated by repeated throat suction, oxygen inhalation, fluid and antibiotic administration via intravenous route. Vitamin $\mathrm{K}$ was given to all of them. All were operated upon. Retropleural approach was adopted for right sided thoracotomy through 4th intercostal space. They were arbitrarily divided into 3 groups according to gap length measured per operatively with a caliper. In Group I gap length was $<2 \mathrm{~cm}$, group II $(2-3 \mathrm{~cm})$ and Group III (> $3 \mathrm{~cm})$. The gap length was measured without mobilization of oesophagus. Tracheoesophageal fistula was identified and closed with 4/0 silk stitches. Single layer end to end oesophageal anastomosis was performed after adequate mobilization of proximal oesophageal segment. Interrupted 4/0 silk stitches were applied for anastomosis. Transanastomotic nasogastric tube was used in all cases. Subjective assessment of tension at the anastomotic site was made. Nasogastric feed was started on third postoperative day. Perianastomotic drain (chest tube) was also placed in all cases. Admission for intensive care unit done for all patients, upper gastrointestinal contrast study in the form of swallow using water soluble contrast done in the seventh postoperative day. Follow up of the survivors was upto one year. Demographic, clinical and operative and postoperative data of the patients were reported and analyzed using the statistical package for social sciences version 16.

\section{Results and Discussion}

The study included 7 male and 18 female babies (Fig. 1). Age at presentation was ranged 5 hours to 20 days (Table 1). Body weight ranged $1.8 \mathrm{~kg}-3.5 \mathrm{~kg}$ (mean: $2.41 \pm$ $0.47) \mathrm{kg}$. Chest infection was reported in $48 \%(12 / 25)$ of cases, and the associated congenital anomalies in 5 cases (20\%) of these 3 cases (12\%) with Gastrointestinal and 2 cases $(8 \%)$ cardiac anomalies (Table 2). The gap length was $<2 \mathrm{~cm}$ in 3 cases (12\%) (Group I), $2-3 \mathrm{~cm}$ in 8 cases (32\%) (group II) and $>3 \mathrm{~cm}$ in 14 cases $(56 \%$ ) (group III), (Table 3) Overall mortality was $12 / 25$ (48\%), major cause of death was sepsis secondary to chest infection (Fig. 2). Among the 13 survived neonates, the postoperative complications were pneumonia in 7 cases (53.8\%), wound infection in 4 cases (30.8\%), anastomotic leak in 3 cases $(23.1 \%)$, gastroesophageal reflux in 2 cases $(15.4 \%)$ and stricture formation in one case $(7.7 \%)$, from other point of view, more than one complication have been developed in some cases (Table 4). However, all patients with complications were treated conservatively except one case need reoperation. It had been found that mortalities were more frequent in cases with wider gap length and the mortality increased with the wider gap; none of the cases in group I (gap length < $2 \mathrm{~cm}$ ) died compared to $3 / 8(37.5 \%)$ in group II (gap length $2-3 \mathrm{~cm}$ ) and 9/14 (64.3\%) in group III (gap length $>3 \mathrm{~cm}$ ) (Table 5). Furthermore among survival, the postoperative complications were also associated with wider gap and were more frequent in cases of Groups III followed by those in group II (Table 6).

According to our findings females were the dominantly affected with EA/TEF compared to male neonates, while no such difference in survival between both genders, Bal et al., (Bal et al., 2016) found relatively higher incidence among males with a male to female ratio of $41: 39$, with no significant difference between both genders neither in incidence nor survival, despite the higher incidence in females in our study no significant difference between both genders in survival. 
Table.1 Age at presentation of 25 neonates with EA/TEF

\begin{tabular}{|l|c|c|}
\hline Age (day) & No. & $\%$ \\
\hline$<1$ & 5 & 20.0 \\
\hline $1-2$ & 8 & 32.0 \\
\hline $3-4$ & 5 & 20.0 \\
\hline 5 or more & 7 & 28.0 \\
\hline Total & 25 & 100.0 \\
\hline
\end{tabular}

Table.2 Distribution of Associated comorbidities among 25 EA/TEF neonates

\begin{tabular}{|c|c|c|c|}
\hline \multicolumn{2}{|c|}{ Comorbidity } & $\begin{array}{c}\text { No. of } \\
\text { cases }\end{array}$ & $\%$ \\
\hline \multicolumn{2}{|c|}{ Chest infection } & 12 & 48.0 \\
\hline \multirow{2}{*}{$\begin{array}{l}\text { Congenital } \\
\text { anomalies }\end{array}$} & Gastrointestinal & 3 & 12.0 \\
\hline & Cardiac & 2 & 8.0 \\
\hline \multicolumn{2}{|l|}{ None } & 8 & 32.0 \\
\hline \multicolumn{2}{|l|}{ Total } & 25 & 100.0 \\
\hline
\end{tabular}

Table.3 Gap length of EA/TEF neonates

\begin{tabular}{|c|c|c|}
\hline Gap length (cm) & No. of cases & $\%$ \\
\hline$<2$ & 3 & 12.0 \\
\hline $2-3$ & 8 & 32.0 \\
\hline$>3$ & 14 & 56.0 \\
\hline Total & 25 & 100.0 \\
\hline
\end{tabular}


Table.4 Post-operative complications among the 13 survived EA/TEF neonates*

\begin{tabular}{|l|c|c|}
\hline Complication & No. of cases & $\%$ \\
\hline Pneumonia & 7 & $53.8 \%$ \\
\hline Wound infection & 4 & $30.8 \%$ \\
\hline Anastomotic leak & 3 & $23.1 \%$ \\
\hline Gastroesophageal reflux & 2 & $15.4 \%$ \\
\hline Stricture formation & 1 & $7.7 \%$ \\
\hline
\end{tabular}

*Some cases had more than one complication at the same time

Table.5 Distribution of mortality and survival according to the gap length

\begin{tabular}{|l|c|c|c|c|c|c|}
\hline \multirow{4}{*}{ Outcome } & \multicolumn{6}{|c|}{ Gap length } \\
\cline { 2 - 7 } & \multicolumn{2}{|c|}{$\begin{array}{c}<\mathrm{cm} \\
(\mathrm{n}=3)\end{array}$} & \multicolumn{2}{c|}{$\begin{array}{c}2-3 \mathrm{~cm} \\
(\mathrm{n}=8)\end{array}$} & \multicolumn{2}{c|}{$\begin{array}{c}>3 \mathrm{~cm} \\
(\mathrm{n}=14)\end{array}$} \\
\cline { 2 - 7 } & No. & $\%$ & No. & $\%$ & No. & $\%$ \\
\hline Survived & $\mathbf{3}$ & 100.0 & $\mathbf{5}$ & 62.5 & $\mathbf{5}$ & 35.7 \\
\hline Died & $\mathbf{0}$ & 0.0 & $\mathbf{3}$ & 37.5 & $\mathbf{9}$ & 64.3 \\
\hline Total & $\mathbf{3}$ & 100.0 & $\mathbf{8}$ & 100.0 & $\mathbf{1 4}$ & 100.0 \\
\hline
\end{tabular}

Table.6 Distribution of postoperative complications according to the gap length of survived neonates $(\mathrm{N}=13)^{*}$

\begin{tabular}{|l|c|c|c|c|c|c|}
\hline \multirow{2}{*}{ Complication } & \multicolumn{2}{|c|}{$\begin{array}{c}<\mathrm{cm} \\
(\mathrm{n}=3)\end{array}$} & \multicolumn{2}{c|}{$\begin{array}{c}2-3 \mathrm{~cm} \\
(\mathrm{n}=5)\end{array}$} & \multicolumn{2}{c|}{$\begin{array}{c}>\mathrm{cm} \\
(\mathrm{n}=5)\end{array}$} \\
\cline { 2 - 8 } & No. & $\%$ & No. & $\%$ & No. & $\%$ \\
\hline Pneumonia & 1 & 33.3 & 2 & 40.0 & 3 & 60.0 \\
\hline Wound infection & 1 & 33.3 & 1 & 20.0 & 2 & 40.0 \\
\hline Anastomotic leak & 0 & 0.0 & 0 & 0.0 & 2 & 40.0 \\
\hline Gastroesophageal reflux & 0 & 0.0 & 1 & 20.0 & 1 & 20.0 \\
\hline Stricture formation & 0 & 0.0 & 0 & 0.0 & 1 & 20.0 \\
\hline
\end{tabular}

* Some cases had more than one complication at the same time 
Fig.1 Gender distribution of the studied group (male: female ratio is 7:18)

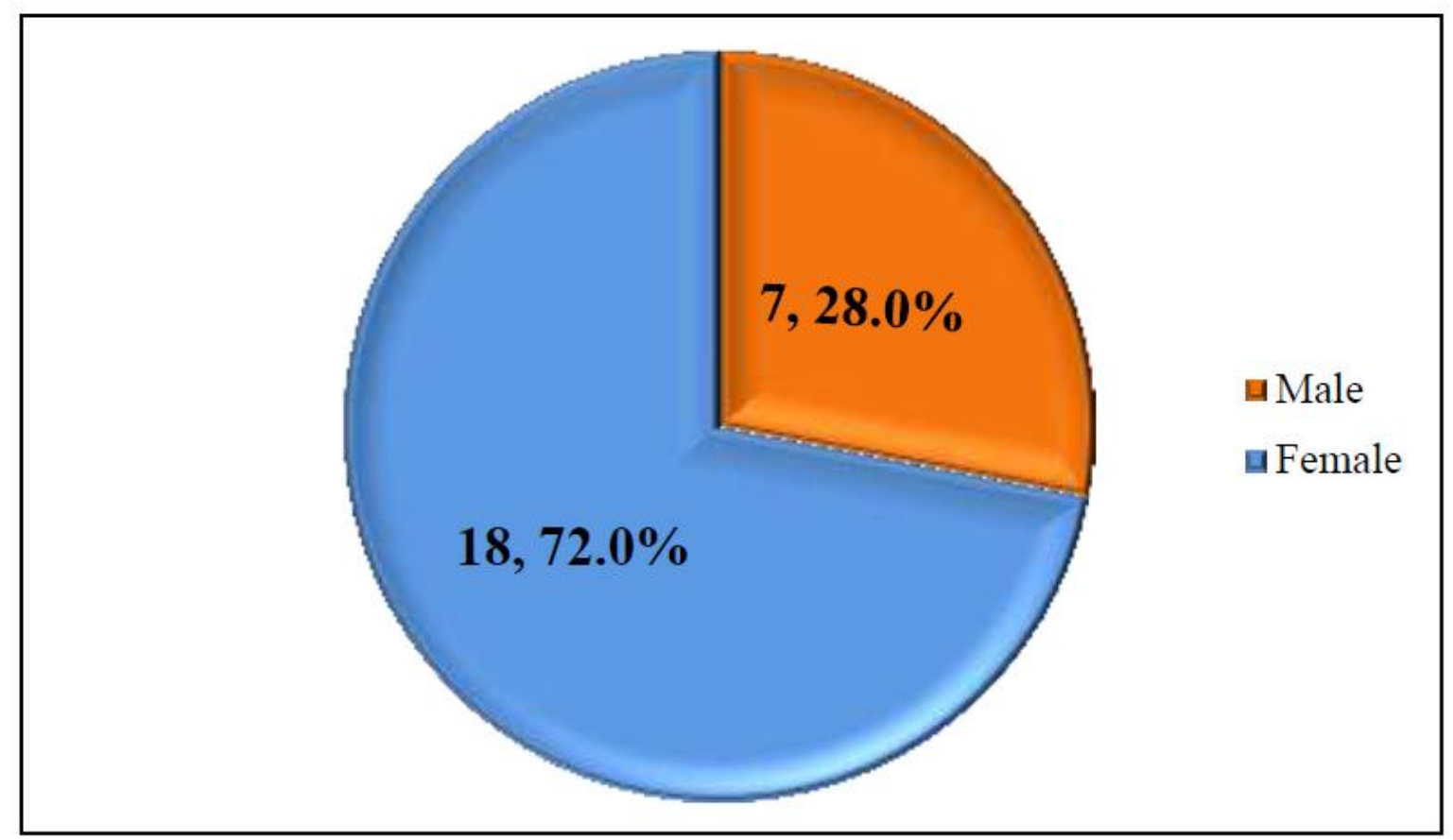

Fig.2 Distribution of the 25 neonates presented with EA/TEF according to the outcome

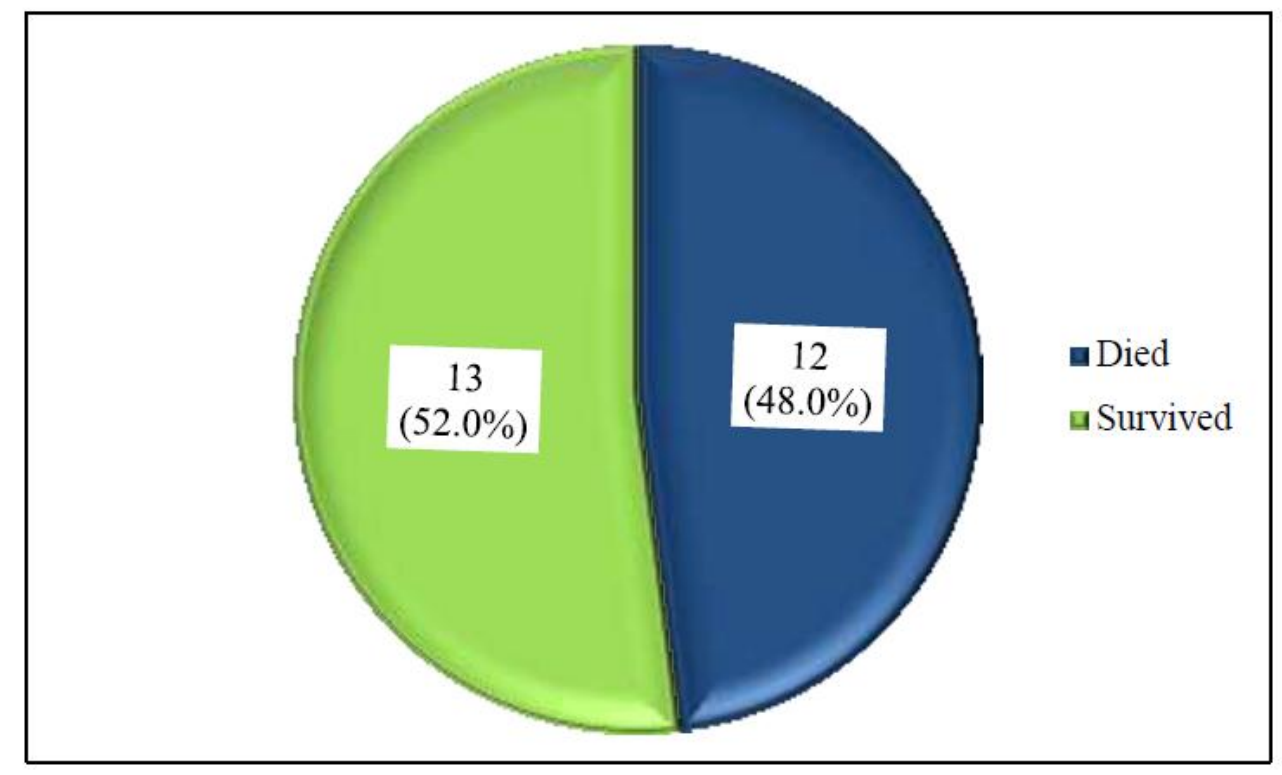

Associated anomalies and comorbidities were reported in $10 / 25$ (40\%) neonates, which is comparable to that reported by Stoll et al., (Stoll et al., 2009) and. Bal et al., (Bal et al., 2016). Previous studies refereed that the gap length is a critical factor affecting the outcome, on the other hand the distance between the two ends of esophagus play an important role in the management; for instance the gap length of less than $2 \mathrm{~cm}$ could be overcome by local mobilization only (Scott 2014), while the difficulties faced by surgeons in the wider gap, additionally no distinct cut off point for the definition of wide gap and this remain subjected to the opinion of surgeon to be considered as long, ultra long or else (Boyle, Irwin, and Foker 1994; Mansur et al., 2005) 
However there are different maneuvers recommended to overcome a wide gap such as tubularisation of the upper pouch after creating a flap, circular myotomy of the upper pouch or abandoning any attempt at initial primary anastomosis awaiting delayed primary anastomosis 6-12 weeks later (Gough 1980; Livitidis 1973; Puri et al., 1981; Spitz 2007). Regarding mortality it was high in our study and the higher mortality among those with gap length of more than $3 \mathrm{~cm}$, the higher overall mortality in our study could be attributed to the larger number of neonates who had wide gap length of more than $3 \mathrm{~cm}$, when compared to previous studies, Brown et al., in their series reported higher mortality rates among those with a gap of more than $3 \mathrm{~cm}$, but the overall mortality in that study lower than ours. The main postoperative complications among the 13 survived neonates included pneumonia, wound infection, anastomotic leak, gastroesophageal reflux and stricture formation were comparable to previous studies (Brown and Tam 1996; Mansur et al., 2005) as these postoperative outcomes are mainly reported in cases with EA with or without TEF. From other point of view, the complications were more frequent with the wider gap, more than $3 \mathrm{~cm}$, these findings supported that reported by Mansur et al., (Mansur et al., 2005) from Egypt and other earlier studies (Bal et al., 2016; Brown and Tam 1996; Livitidis 1973; Puri et al., 1981). The current study suggested that the length of the gap could be a good predictor for the outcome of neonates with EA/TEF, however further studies and further investigations are necessary to explicit the definite predictive role.

The gap length could predict the clinical outcome of newborns with EA/TEF. Nonetheless further stdies with larger sample size are highly suggested for further assessment of the role of gap length and its effect on the outcome.

\section{Acknowledgement}

Author acknowledge everybody who gave hand to complete this study, also best regards to the care givers of the cases who agreed to participate in this study, I hope their babies get better and good life, and for those who lost their babies, I hope they will be compensated by Allah (God), hoping good luck to them. Thanks and regards to Dr. Hameed K. Al-Hadrawy, Community Medicine Specialist Physician, Head of the Researches and development Training Unit, Al Sader Medical City for his efforts in the statistical analysis and presentation of findings. Great thanks and best regards to the Medical and Paramedical staff of the operation room and NICU for their cooperation and help.

\section{References}

Bal, Harshjeet Singh et al., 2016. - An Assessment of Quality of Life of Operated Cases of Esophageal Atresia in the Community.ll Journal of Indian Association of Pediatric Surgeons 21(3): 131-38. http://www.ncbi.nlm.nih.gov/pmc/articles/PMC489 $5739 /$.

Boyle, Edward M, Eric D Irwin, and John E Foker. 1994. -Primary Repair of Ultra-Long-Gap Esophageal Atresia: Results without a Lengthening Procedure.l TheAnnals of thoracic surgery 57(3): 576-79.

Brown, A.K., and P K Tam. 1996. -Measurement of Gap Length in Esophageal Atresia: A Simple Predictor of Outcome.ll Journal of the American College of Surgeons 182(1): 41-45.

Foker, John E., Bradley C Linden, Edward M Boyle Jr, and Cathleen Marquardt. 1997. —Development of a True Primary Repair for the Full Spectrum of Esophageal Atresia.ll Annals of surgery 226(4): 533.

Gough, Malcolm H., 1980. -Esophageal Atresia-use of an Anterior Flap in the Difficult Anastomosis.l Journal of pediatric surgery 15(3): 310-11.

Kim, Soo-hong et al., 2017. -Clinical Study of Congenital Esophageal Stenosis: \|| 20(2): 79-86.

Livitidis, A., 1973. -Esophageal Atresia: A Method of Overbrindging Large Segment Gaps.\| Z Kinderchir 13: 298-306.

Mansur, S Haroon, Nabila Talat, Sarfraz Ahmed, and Sarfraz Ahmed. 2005. Oesophageal Atresia: Role of Gap Length in Determining the Outcome. Biomedica 21(5): 125-28.

Nassar, Natasha et al., 2012. - Prevalence of Esophageal Atresia among 18 International Birth Defects Surveillance Programs.ll Birth Defects Research Part A - Clinical and Molecular Teratology 94(11): 893-99.

Pinheiro, Paulo Fernando Martins; Ana Cristina Simoes e Silva, Regina Maria Pereira, and Regina Maria Pereira. 2012. - Current Knowledge on Esophageal Atresia.ll World Journal of Gastroenterology 18(28): 3662-72.

Puri, P., N Blake, B O’Donnell, and E J Guiney. 1981. -Delayed Primary Anastomosis Following Spontaneous Growth of Esophageal Segments in Esophageal Atresia. Journal of pediatric surgery 16(2): 180-83.

Rankin, J., et al., 2005. - Prevalence of Congenital Anomalies in Five British Regions, 1991-99.॥ 
Archives of disease in childhood. Fetal and neonatal edition 90(5):

F374-9. http://fn.bmj.com/cgi/content/long/90/5/F374.

Scott, Daryl A., 2014. -Esophageal Atresia and Tracheoesophageal Fistula. American Family Physician 59(4): 910-16. http://fn.bmj.com/cgi/content/long/90/5/F374.

Seitz, Guido et al., 2006. - Primary Repair of Esophageal Atresia in Extremely Low Birth Weight Infants: A Single-Center Experience and Review of the Literature. Biology of the Neonate 90(4): 24751.

Spitz, L., 2007. -Oesophageal Atresia.\| Orphanet journal of rare diseases 2: 24. http://www.ncbi.nlm.nih.gov/pubmed/17498283.

Stoll, Claude, Yves Alembik, Beatrice Dott, and Marie Paule Roth. 2009. Associated Malformations in Patients with Esophageal Atresia. European Journal of Medical Genetics 52(5): 287-90. http://dx.doi.org/10.1016/j.ejmg.2009.04.004.

\section{How to cite this article:}

Hayder Neamah Hassan Al-Khayyat. 2017. Esophageal Atresia and Tracheoesophageal fistula: Gap Length and Clinical Outcome (A Prospective Study among Group of Iraqi Neonates). Int.J.Curr.Res.Aca.Rev. 5(8), 60-66. doi: https://doi.org/10.20546/ijcrar.2017.508.009 